\title{
Employment Analysis and Countermeasures of Land-lost Farmers after Urbanization
}

\author{
Zihao Chen ${ }^{1, a,{ }^{*}}$ and Yixiang Dai ${ }^{2, b}$ \\ ${ }^{1}$ School of Business Administration, Hohai University, Changzhou, China \\ ${ }^{2}$ School of Business Administration, Hohai University, Changzhou, China \\ a495552185@qq.com, b2356204061@qq.com \\ *Corresponding author
}

Keywords: Rural Revitalization, Urbanization, Land-lost Farmers, Employment

\begin{abstract}
In recent years, under the background of rural revitalization, many places have realized the rapid development of urbanization through the transfer and agglomeration of villages to central urban areas or central towns, which enables a large number of rural residents to enter towns and enjoy equal access to urban public services. However, when farmers move to towns, it also means that a large number of farmers become landless farmers, resulting in a large number of employment demands. This paper introduces the connotation and implementation path of China's urbanization, analyzes the employment situation of land-lost farmers and gives corresponding countermeasures.
\end{abstract}

\section{Introduction}

On October 18, 2017, Chinese President Xi Jinping clearly puted forward the strategy of rural vitalization at the 19th CPC National Congress, continuing to solve "three rural issues" and inject new vitality into rural development. The strategy of rural vitalization is an explanation and promotion of rural modernization, and rural modernization is a key part of the strategy of rural vitalization. There are three basic ways to achieve rural modernization, including industrial modernization, agricultural modernization and urbanization. This is mainly reflected in the growth of rural economy, the improvement of rural residents' income and the development of rural urbanization.

The realization of rural urbanization is an important way to realize the rural revitalization strategy and rural modernization, as well as an important way to realize the "urban-rural integration", urban and rural public services and social equity in the strategy of rural vitalization. In 2014, the State Council of the PRC issued "National Plan on New Urbanization”, accelerating the process of realizing national urbanization. Urbanization rate refers to the proportion of permanent urban residents in a region in the total population. The relocation of population to central cities or towns can rapidly improve the urbanization rate of this region, save a lot of land resources, promote the economic growth of central cities and towns, and promote the development of "urban-rural integration". China's urbanization rate is expected to reach 60 percent by 2020, up 6.4 percentage points from 2014.

According to report on the work of the government, China's urbanization will aim to achieve the goal of "three 100 million people": By implementing the reform of the household registration system, about 100 million eligible and willing agricultural migrants will be settled in cities and towns; By accelerating the development and urbanization in the central and western regions, about 100 million people will be employed in the central and western regions; Improving the living conditions of about 100 million permanent residents living in shantytowns and villages through intensified efforts to upgrade shantytowns and villages. China's urbanization rate is expected to reach 60 percent by 2020, up 6.4 percentage points from 2014 . 


\section{Employment dilemma faced by land-lost farmers}

Different from the urbanization caused by the migration of rural population to cities brought by normal natural economic development, such rapid urbanization will make the problems in urbanization more prominent after it leads to the increase of urbanization rate.

The employment problems are particularly acute:

\subsection{Lack of employment position}

After the urbanization of rural residents, they will also be far away from land and primary industry, which will lead to the transfer of a large number of labor force from primary industry in a short time. However, the central cities and towns cannot bring in or produce the second and third industries in a short time to provide enough jobs for the new large number of urban population.

\subsection{Lack of vocational skills}

The population transferred from the land and primary industry is mainly farmers who have been engaged in farming before, with a low level of education culture and a lack of occupational skills and experience in the secondary and tertiary industries. Nor, for a short time, can public or private institutions in cities and towns provide vocational training for large Numbers of people. According to the sixth national census in 2010, the population of China is mainly in junior and primary schools at education level, accounting for $65.57 \%$ of the total population. The proportion of higher education is only $8.93 \%$, which is still far behind the average of populous countries.

\subsection{Low levels of labor force}

In terms of the proportion of population transferred, it is also mainly women and the elderly, whose labor force capacity is relatively lower than that of young and middle-aged men. Since young and middle-aged men have been working in cities, the population left behind to work at home is mainly women and the elderly. It increased requirements for the industry and structure of demanding positions.

\subsection{Lack of ability to attract industry}

The agglomerated villages and the displaced population, mostly in accordance with the principle of proximity, move and relocate to the township of the town to which the countryside belongs, A small number of villages, closer to central urban areas, moved to the suburbs of central urban areas. The infrastructure in the suburbs of towns and central cities is relatively backward and less attractive to various businesses. In the case of relatively backward industrialization, local enterprises are faced with such problems as small number, small scale and insufficient capital, which ultimately leads to insufficient employment.

\section{Countermeasures}

Employment is the foundation of people's livelihood, especially for the farmers who lost their land and transferred from the primary industry. The solution of employment problem is conducive to social stability, economic development and the construction of a harmonious society.

Based on the above problems, the solution is proposed:

3.1. Undertake the transfer of labor-intensive industries in developed areasIndustrialization is not only the biggest driving force of urbanization, but also the foundation for the stable development of cities and towns after urbanization. In recent years, with the development of national economy, the labor cost and land cost of the industries in developed areas have been increasing. Coupled with the national requirements for industrial transformation and upgrading, the labor-intensive industries in developed areas are in urgent need of transferring to areas with low labor costs, low land costs and abundant labor. It is consistent with the characteristics of cheap land, concentrated and cheap labor force, huge employment demand and preferential government policies 
in the areas undergoing rural urbanization. Therefore, the local government should actively operate to seize opportunities, attract investment and undertake the transfer of labor-intensive industries from developed regions. On the one hand, it can greatly alleviate the employment problem after rapid urbanization, improve the income of rural residents after urbanization and promote local economic development. On the other hand, it can increase government taxes, increase investment funds for infrastructure, improve local infrastructure, provide better conditions for further investment, and finally form a virtuous circle.

\subsection{Establish a mature employment training system}

Labor force contains the increase of human capital, which is conducive to improving the competitiveness of labor force in the employment market and promoting employment. By means of vocational skills training, formal culture education and industry experience imparting, the human capital of the labor force can be effectively increased.

After urbanization, the lack of professional skills, low education level, is the most direct manifestation of land-lost farmers' low human capital. Without a mature employment training system and a scientific growth mechanism, the transferred labor force cannot meet the requirements of employment conditions. At the same time, they can only engage in low-end industries, which will hinder their career development and form a huge obstacle to the local industrial upgrading in the future, thus making the region Mired in low-end industries.

Due to the backwardness of farmers' employment concepts, they have neglected employment training for a long time. And the high cost of employment training makes the farmers who have received the concept of training prohibitive to employment training. At this time, the role of the government is particularly important.

(1) The government needs to increase publicity and change the attitudes of rural residents. Government should also attach great importance to the training of farmers' employment and vocational skills, stimulate land-lost farmers' desire for professional knowledge, and encourage land-lost farmers to continue to carry forward their traditional spirit of hardworking and industrious wisdom, so that they can continue to play an important role in the new industry.

(2) The government shall organize the establishment of employment training institutions, allocate special funds from the finance for the establishment of public employment training institutions, and provide regular employment or specialized vocational training to the public. It should be noted that the training contents should be targeted, long-term and stable according to the characteristics of land-lost farmers' shortage of professional skills. In addition, the content of job training should be based on serving existing local industries or planned industries in the future, and should be compatible with industrial development needs. Only in this way can farmers make use of their knowledge, reduce the waste of public resources and improve the utilization rate of public resources. At the same time, it can also greatly save people's time and energy and truly provide convenience and services for people.

(3) Give play to the power of private knowledge and capital; encourage private employment training institutions. On the one hand, when confronted with heavy financial burden and too many people to be trained, government can divert the through the purchase of private employment training institutions. This approach can also effectively expand the scale of employment training. On the other hand, we should give full play to the power of private vocational knowledge and work experience to provide more choices to the people who need employment training and vocational training. Meanwhile, the training content can also be diversified to enrich human capital for employees in more industries.

\subsection{Encourage the development of rural collective enterprises and service industries that serve local consumption}

The development of township enterprises is an important way to solve employment problems. We should encourage the development of township collective enterprises, make full use of the power of 
private capital, and concentrate dispersed private capital so that the development of enterprises has sufficient capital. Expand enterprise scale by introducing advanced technology and attracting high-quality talents; Make full use of the advantages of concentrated cheap labor force and large employment demand; According to the local characteristics of the township, develop their own characteristic industries to seek asymmetrical advantages in the market competition.

Another feature of the large population concentration in the township is that it provides a large consumer market. We will actively encourage the development and input of the service sector on the basis of the full consumer market.

Before the population concentration, the service industry which has no input and development due to the shortage of market demand can be started up by taking advantage of opportunities. In addition, Backward areas should learn advanced experience and trends from developed regions and introduce services that meet the local consumption level. By utilizing the market demand to develop the service industry, it can provide a large number of jobs, effectively alleviate the employment problem and improve the living standard of local residents. These methods play a major role in promoting local economic development.

\section{Summary}

In this paper, we analyze the employment situation of land-lost farmers after rapid urbanization, and find some serious problems: Lack of employment position, lack of vocational skills, low levels of labor force, and lack of ability to attract industry. By learning from experience and researching, we believe that employment problems can be solved by a series of measures, such as transferring labor-intensive industries in developed regions, establishing a mature employment training system, encouraging the development of rural collective enterprises and service industries that serve local consumption.

\section{References}

[1] Aihua Mao. Study on Employment and Guarantee of Rural Land-lost Farmers, Labor Security World, vol. 33, pp. 34+40, 2018.

[2] Ruyv Wang. Analysis on the Restrictive Factors and Policy Support of Landless Farmers' Employment, Rural Economy and Science, vol. 18, pp. 165+167, 2018.

[3] Yongmin Zhang and Liyan Li. On the Employment of Landless Farmers under the Background of Urbanization, Rural Economy, vol. 05, pp. 72-73, 2018.

[4] Jiqian Ma. The Impact of Labor Market Segmentation on the Employment of Landless Farmers, East China Economic Management, vol. 12, pp. 178-184, 2017. 